\title{
Occurrence, overall rate and prognosticators of acute poisoning in emergency department of Mettu Karl Referral Hospital, Southwest Oromia, Ethiopia: A retrospective cross-sectional study
}

\author{
Gudisa Bereda ${ }^{1 *}$ and Gemechis Bereda ${ }^{1}$ \\ ${ }^{1}$ SWAN Diagnostic Pharmaceutical Importer, Addis Ababa, Ethiopia
}

\begin{abstract}
Background: Acute poisoning is a substance that causes harmful effect when administered by accident or by design to a living organism. Acute poisoning is a major medical emergency that carries significant morbidity and mortality in patients of all age groups across the world. Exposure to agrochemicals, medicines and environmental agents are the major causes of poisoning. Distress due to loss in the business, failure in romance or differences with the intimate partner or examination, emotional disturbances and chronic diseases are the common reasons for intentional poisoning.

Objective: To expose occurrence, overall rate and prognosticators of acute poisoning in emergency department of Mettu Karl Referral Hospital.

Methods: A retrospective cross sectional study design was carried out from March 22, 2020, to April 28, 2021. Data was collected through employing well-structured questioner, and the data was entered and analyzed through statistical packages of social sciences 25.0 version statistical Software. Associations between categorical variables were established from the chi-square test. Categorical variables were summarized as counts and percentages.

Results: A total of 76 patients were enrolled and studied. From the total patients studied,44 (57.9\%) participants were males. The present study revealed that from poisoning substances pesticides 20(26.3\%) were highly identified followed by rat poisoning chemicals $15(19.8 \%)$. The prevalence of acute poisoning death was $27.6 \%$ ( 21 cases). Victims whose age between $0-12$ years $\left(\chi^{2}=3.10, p=0.007\right)$, being female $\left(\chi^{2}=1.87, p=0.005\right)$, dwell in rural area $\left(\chi^{2}=4.5\right.$, $\left.p=0.001\right)$, divorced marital status $\left(\chi^{2}=1.79, p=0.005\right)$, and living in house alone $\left(\chi^{2}=3.21, p=0.049\right)$ were the significantly predictors associated with the occurrence of acute poisoning.

Conclusion and recommendations: The prevalence of acute poisoning was high in the victims drunk the pesticides during the summer season. A majority of acute poisoning patients were survived without disability and only few victims were died. Creating awareness about proper handling of chemicals and prescribed drugs in the society should be design and implemented by FMOH and also Mettu Karl Referral Hospital should have to advice the community, through different mechanisms especially for the youth.
\end{abstract}

\section{Introduction}

The word poison originates from the Latin word potionem which means deadly draught. The Herald of modern Toxicology, Paracelsus, supposed that everything is poison and only the dose plays a pivotal role. Any substance when ingested in large quantities can be toxic. Poison may be defined as any agent that can injure, kill or impair normal physiological function in humans producing general or local damage or dysfunction in the body by its chemical activity [1]. Poisoning occurs by the absorption of chemical, physical, or organic substances into the body through the gastrointestinal tract, skin, mucosa or respiratory tract or parentally causing damage to the cell, tissue and organs. Poisoning is a common medico-social problem all over the world which may result in morbidity and mortality. Knowledge of the epidemiology of poisoning and its changes is important to both emergency physicians and public health practitioners [2]. Acute poisoning is a dynamic medical illness usually representing an acute and potentially lifethreatening exacerbation of a chronic underlying psycho-social disorder [3]. It is a common reason for visits to emergency departments and for hospitalization worldwide and it is a cause of both morbidity and mortality in many parts of the world. Globally it is estimated that poisoning events are responsible for more than one million illnesses annually [4]. Patients with acute poisoning have highly variable clinical presentations, making diagnosis difficult, especially in resource limited settings [5]. The prevalence, nature, mortality, and morbidity of acute poisoning vary owing to differences in socioeconomic, cultural, and health care facility level of the country [6]. Regarding the prevalence of acute poisoning in the world various retrospective hospital-based studies showed that there was a variation. For instance, a retrospective analysis of acute poisoning conducted in Iran-Tehran reported a prevalence of 5.4\% [7], While in Kenya it was $0.07 \%$ [8]. Several factors can contribute to the wide difference in poisoning pattern such

${ }^{*}$ Correspondence to: Gudisa Bereda, SWAN Diagnostic Pharmaceutical Importer, Addis Ababa, Ethiopia, Tel: +251919622717; E-mail: gudisabareda95@ gmail.com

Key words: Acute poisoning, Occurrence, Overall Rate, Prognosticators, Emergency Department, Mettu Karl Referral Hospital, Ethiopia

Received: May 15, 2021; Accepted: June 21, 2021; Published: June 28, 2021 
Bereda G (2021) Occurrence, overall rate and prognosticators of acute poisoning in emergency department of Mettu Karl Referral Hospital, Southwest Oromia, Ethiopia: A retrospective cross-sectional study

as climate (for carbon monoxide poisoning), socio economic factors, cultural (traditional remedies versus medical advice and products), ethnic variations and religious beliefs prevalent in the community [9].

The WHO estimates that poisoning results in an annual loss of 7.4 million years of healthy life DALYs globally. However, this burden dis proportionally impacts low and middle-income countries, where over ninety percent of deaths due to unintentional poisoning occur [10]. There are striking differences in the pattern of poisoning between developed countries and developing agricultural countries [11]. Morbidity and mortality because of acute poisoning is a worldwide problem; however, its impact may be more on poor countries Absorption of a poison is necessary for systemic poisoning. It is estimated that some forms of poisons are directly or indirectly responsible for more than 1 million illnesses worldwide annually [12]. Poisoning is a significant global public health problem and cases are increasing day to day due to changes in the lifestyle and social behaviour. Advances in technology and social development have resulted in the availability of most drugs and chemical substances in the community. The exact number of incidences can be higher, because most cases of poisoning actually go unreported [13]. More than 300,000 people die every year from pesticide poisoning all over the world. The commonest causes are organo phosphates and ALP [14]. There are few studies on prevalence of acute poisonings in Ethiopia. This is because most of the screening \& confirmatory tests are not done routinely in available set-ups within the country. The existing little hospital-based studies revealed that the case fatality rate was reported to range from $2.4 \%$ to $8.6 \%$. Despite the rapidly growing role of chemicals in the country, lack of poison centres and toxicological expertise among health professionals may increase the likelihood of adverse health impacts of acute poisoning to the public [15]. In Ethiopia currently there is increasing incidences of acute poisoning which range from ingestion of home cleansing bleach, illicit brews consumption and use of uncertified herbal medicine for treatments and unsafe abortion. The findings of this study will be valuable in understanding the capabilities of ED nurses in management of these patients. Furthermore, the study will form a basis for improving the quality-of-service delivery in management of poisoned casualties at ED by nurses as a whole in Ethiopia.

\section{Methodology}

\section{Study area and period}

The study was conducted in MKRH, Mettu town, Southwest oromia, Ethiopia which is found at $600 \mathrm{~km}$ from Addis Ababa. There are different wards and clinics within $\mathrm{MKRH}$; those include internal medicine ward, surgery ward, pediatric ward, anti-retroviral therapy clinic and gynaecology, obstetrics ward, Antenatal clinic, dental clinics, tuberculosis clinic, and ophthalmologic clinic. The study was conducted from March 22, 2020, to April 28, 2021.

\section{Study design}

A retrospective cross sectional study design was being used.

\section{Inclusion and exclusion criteria}

All pediatrics and adult patients who were acutely poisoned and presented to emergency department were included in the study. Both pediatrics and adult patients whose medical records were found to be incomplete, completely lost or misplaced were not included in the study were excluded.

\section{Sample size calculation and sampling technique}

The sample size was calculated based on single population proportion formula by assuming that confidence interval $=95 \%$, where
$\mathrm{Za} / 2$ of $95 \%=1.96$, $p$-value was taken from Ethiopia, $p=78 \%$ a, and $\mathrm{D}=5 \%$ then,

$$
n=\frac{(z a / 2)^{2} p(1-p)}{d^{2}}, n=\frac{(1.96)^{2}(1-0.78)}{(0.05)^{2}}=264
$$

Since the total number of poisoned patients were less than 10,000 , reduction formula (correction formula) was applied as follow; $\mathrm{n}_{\mathrm{f}}=\mathrm{n}$ / $(1+(n / N)), n_{f}=264 /(1+(264 / 94)=69$. When $10 \%$ contingency is added to minimize nonresponse rate, then final sample size was found to be 76. A simple random sampling technique was applied to select the poisoned victim's medical charts by lottery method from the victim's medical registration logbook.

\section{Study variables}

The outcome variable was prevalence of acute poisoning and predictors variables were socio demographic factors (age, sex, educational status, monthly income, marital status, family size), poison related characteristics (season of acute poisoning, type of poisoning substance, type of poisoning, reason of acute poisoning).

\section{Data collection process}

A well-structured standard checklist and questionnaire was used to collect relevant information from patient charts. Data was extracted from all eligible patient medical charts and registries. The data collection tool contains patient socio-demography, poisoning substances identified, type of poisoning occurred, season and reason of poisoning, type of treatment given and outcome of the incidence. All the data collection process was conducted by the recruited nurses and monitored by the PI at the hospital.

\section{Data quality control}

In order to assure quality of data important measures was undertaken including the patient card number was used to check for if there is invalid and incomplete pertinent response and these cards were also coded so over or under count was not matter. The data collected was checked for completeness and consistency on daily basis.

\section{Statistical methods}

The data was entered and analyzed through statistical packages for social sciences 25.0 version statistical software. Bivariate and multivariate analysis was done to see association of factors with mortality. Descriptive statistic was presented as frequency percentages for categorical variables and mean with standard deviation for numerical Variables. A P-value less than 0.05 was cut point to say there was a positive association between the dependent and independent. Finally, the result was presented using frequency, percentage, tables, and graphs.

\section{Ethical considerations}

Ethical approval was obtained from SWAN diagnostic pharmaceutical importer. Behind the scenes of patients were maintained at all levels of the study as the data abstraction format does not disclose patient identifiers.

\section{Operational Definitions}

Acute poisoning is when the body is exposed to a toxic substance in a high dose, on one occasion and during a short period of time. Symptoms develop in close relation to the exposure. 
Bereda G (2021) Occurrence, overall rate and prognosticators of acute poisoning in emergency department of Mettu Karl Referral Hospital, Southwest Oromia, Ethiopia: A retrospective cross-sectional study

Table 1. Socio-demographic characteristics of patients who admitted to the ED of MKRH, $2021(n=76)$

\begin{tabular}{|c|c|c|c|}
\hline Variables & Category & Frequency & Percent \\
\hline \multirow{4}{*}{ Age } & $0-12$ years & 27 & 35.5 \\
\hline & $13-19$ years & 21 & 27.6 \\
\hline & 20-30 years & 17 & 22.4 \\
\hline & $>30$ years & 11 & 14.5 \\
\hline \multirow{2}{*}{ Sex } & Male & 32 & 42.1 \\
\hline & Female & 44 & 57.9 \\
\hline \multirow{2}{*}{ Residency } & Urban & 36 & 47.4 \\
\hline & Rural & 40 & 52.6 \\
\hline \multirow{4}{*}{ Marital status } & Single & 30 & 39.5 \\
\hline & Married & 14 & 18.4 \\
\hline & Divorced & 20 & 26.3 \\
\hline & Widowed & 12 & 15.8 \\
\hline \multirow{2}{*}{ Educational status } & Uneducated & 50 & 65.8 \\
\hline & Educated & 26 & 34.2 \\
\hline \multirow{4}{*}{ Living condition } & $\begin{array}{l}\text { Living in house } \\
\text { alone }\end{array}$ & 34 & 44.7 \\
\hline & $\begin{array}{l}\text { Living alone on } \\
\text { street }\end{array}$ & 6 & 7.9 \\
\hline & $\begin{array}{l}\text { Living with family/ } \\
\text { friends }\end{array}$ & 19 & 25.0 \\
\hline & Others & 17 & 22.4 \\
\hline
\end{tabular}

\section{Results}

Disability is to mean either physical disability or physiological disability leading to dialysis or respiratory failure following acute poisoning.

Poisoning is a qualitative term used to define the potential of a chemical substance acting adversely or deleteriously on the body by interfering with normal body functions after it is swallowed, inhaled, injected, or absorbed.

\section{Socio-demographic characteristics of patients}

A total of 76 patients were enrolled and studied. From the total patients studied, 44 (57.9\%) participants were males. The majority age of patients was between $0-12$ years $27(35.5 \%)$ followed by $13-19$ years $21(27.6 \%)$. Concerning marital status majority $30(39.5 \%)$ of patients were single and $20(26.3 \%)$ were divorced. Above half $36(52.6 \%)$ of the patients were dwelled in rural area and $50(65.8 \%)$ of the patients were uneducated. A majority $34(44.7 \%)$ of participants were living alone in house and 19(25.0\%) were living with family or friends (Table 1).

\section{Contributing factors associated with poisoning among poisoned patients}

The time elapsed since exposure to arrival at hospital of majority $41(53.9 \%)$ patients were $>4$ hours, and majority $34(44.7 \%)$ of participants takes poisoning through oral followed by direct contact $18(23.7 \%)$. Most participants taken the acute poisoning one times $33(43.4 \%)$ followed two times $15(19.7 \%)$. The mode of poisoning in more participants were unspecified $46(60.5 \%)$. The season of acute poisoning were highly occurred in June-Aug (Summer) 35(46.1\%) followed by Dec-Feb (Winter) 21(27.6\%). A majority 31(40.8\%) of
Table 2. Contributing factors associated with poisoning among poisoned patients who admitted to the ED of MKRH, $2021(\mathrm{n}=76)$

\begin{tabular}{|c|c|c|c|}
\hline Variables & Category & Frequency & Percent \\
\hline \multirow{3}{*}{$\begin{array}{l}\text { Time elapsed since } \\
\text { exposure to arrival at } \\
\text { hospital }\end{array}$} & $<2$ hours & 16 & 21.1 \\
\hline & $2-4$ hour & 19 & 25.0 \\
\hline & $>4$ hours & 41 & 53.9 \\
\hline \multirow{4}{*}{$\begin{array}{l}\text { Root of poisoning } \\
\text { Ingestion }\end{array}$} & Direct contact & 18 & 23.7 \\
\hline & Oral & 34 & 44.7 \\
\hline & Inhalation & 10 & 13.2 \\
\hline & Unknown & 14 & 18.4 \\
\hline \multirow{5}{*}{$\begin{array}{l}\text { Frequency of } \\
\text { exposure to toxins }\end{array}$} & One & 33 & 43.4 \\
\hline & Two & 15 & 19.7 \\
\hline & Three & 11 & 14.5 \\
\hline & Four & 12 & 15.8 \\
\hline & Above four & 5 & 6.6 \\
\hline \multirow{2}{*}{ Mode of Poisoning } & Intentional & 30 & 39.5 \\
\hline & Unspecified & 46 & 60.5 \\
\hline \multirow{4}{*}{ Season of Poisoning } & Dec-Feb (Winter) & 21 & 27.6 \\
\hline & March-May (Spring) & 11 & 14.5 \\
\hline & June-Aug (Summer) & 35 & 46.1 \\
\hline & Sept-Nov (Autumn) & 9 & 11.8 \\
\hline \multirow{3}{*}{$\begin{array}{l}\text { Outcome of } \\
\text { Poisoning }\end{array}$} & $\begin{array}{l}\text { Survived without } \\
\text { Disability }\end{array}$ & 31 & 40.8 \\
\hline & $\begin{array}{l}\text { Survived with } \\
\text { Disability }\end{array}$ & 24 & 31.6 \\
\hline & Death & 21 & 27.6 \\
\hline \multirow{2}{*}{ Cause of poisoning } & Deliberate poisoning & 49 & 64.5 \\
\hline & Accidental poisoning & 27 & 35.5 \\
\hline
\end{tabular}

Table 3. Classification of substances taken by patients and type of treatment given to patients who admitted to the ED of MKRH, $2021(\mathrm{n}=76)$

\begin{tabular}{|c|c|c|c|}
\hline Variables & Category & Frequency & Percent \\
\hline \multirow{10}{*}{$\begin{array}{l}\text { Poisoning substances } \\
\text { identified }\end{array}$} & $\begin{array}{l}\text { Organophosphate } \\
\text { Materials }\end{array}$ & 3 & 3.9 \\
\hline & Bleaching Agents & 7 & 9.2 \\
\hline & $\begin{array}{l}\text { Pharmaceuticals } \\
\text { (Drugs) }\end{array}$ & 6 & 7.9 \\
\hline & Pesticides & 20 & 26.3 \\
\hline & $\begin{array}{l}\text { Rat Poisoning } \\
\text { Chemicals }\end{array}$ & 15 & 19.8 \\
\hline & Alcohol Intoxication & 8 & 10.5 \\
\hline & Carbon Monoxide & 5 & 6.6 \\
\hline & Snake Bite & 4 & 5.3 \\
\hline & $\begin{array}{l}\text { Traditional } \\
\text { Medicines }\end{array}$ & 6 & 7.9 \\
\hline & Others & 2 & 2.6 \\
\hline \multirow{9}{*}{$\begin{array}{l}\text { Type of Treatment } \\
\text { given/management } \\
\text { practices }\end{array}$} & Fluid Resuscitation & 21 & 27.6 \\
\hline & $\begin{array}{l}\text { Chelation with } \\
\text { Activated Charcoal }\end{array}$ & 10 & 13.2 \\
\hline & $\begin{array}{l}\text { Antidote } \\
\text { Management }\end{array}$ & 4 & 5.3 \\
\hline & $\begin{array}{l}\text { Whole Bowel } \\
\text { irrigation }\end{array}$ & 1 & 1.3 \\
\hline & Gastric Lavage & 17 & 22.4 \\
\hline & Hemodialysis & 4 & 5.3 \\
\hline & Emesis & 8 & 10.5 \\
\hline & $\begin{array}{l}\text { Medications other } \\
\text { than Antidote }\end{array}$ & 6 & 7.9 \\
\hline & Others & 5 & 6.6 \\
\hline
\end{tabular}


Bereda G (2021) Occurrence, overall rate and prognosticators of acute poisoning in emergency department of Mettu Karl Referral Hospital, Southwest Oromia, Ethiopia: A retrospective cross-sectional study

Table 4. Association of poisoning outcome of socio-demographic characteristics of patients who admitted to the ED of MKRH, $2021(\mathrm{n}=76)$

\begin{tabular}{|c|c|c|c|c|}
\hline Variables & Category & n (\%) & AOR (95\% C.I) & $P$-value \\
\hline \multirow{4}{*}{ Age } & $0-12$ years & $27(35.5)$ & $3.10(2.920-6.321)$ & 0.007 \\
\hline & 13-19 years & $21(27.6)$ & $1.14(1.641-1.907$ & 0.69 \\
\hline & 20-30 years & $17(22.4)$ & $0.85(0.019-1.032)$ & 0.45 \\
\hline & $>30$ years & $11(14.5)$ & \multicolumn{2}{|l|}{ Reference } \\
\hline \multirow{2}{*}{ Sex } & Male & $32(42.1)$ & $1.87(1.941-2.216)$ & 0.005 \\
\hline & Female & $44(57.9)$ & \multicolumn{2}{|l|}{ Reference } \\
\hline \multirow{2}{*}{ Residency } & Urban & $36(47.4)$ & $2.31(2.410-3.819)$ & 0.016 \\
\hline & Rural & $40(52.6)$ & \multicolumn{2}{|l|}{ Reference } \\
\hline \multirow{4}{*}{ Marital status } & Single & $30(39.5)$ & $0.21(0.019-1.132)$ & 0.17 \\
\hline & Married & $14(18.4)$ & $1.13(1.256-1.832)$ & 0.082 \\
\hline & Divorced & $20(26.3)$ & $4.5(4.673-9.312)$ & 0.001 \\
\hline & Widowed & $12(15.8)$ & \multicolumn{2}{|l|}{ Reference } \\
\hline \multirow{2}{*}{ Educational status } & Uneducated & $50(65.8)$ & $0.21(0.032-1.002)$ & 0.76 \\
\hline & Educated & $26(34.2)$ & \multicolumn{2}{|l|}{ Reference } \\
\hline \multirow{4}{*}{ Living condition } & Live in house alone & $34(44.7)$ & $3.21(3.975-7.312)$ & 0.049 \\
\hline & Living alone on street & $6(7.9)$ & $1.74(1.890-2.031)$ & 0.19 \\
\hline & Living with family & $19(25.0)$ & $0.92(0.074-1.253)$ & 0.530 \\
\hline & Others & $17(22.4)$ & \multicolumn{2}{|l|}{ Reference } \\
\hline
\end{tabular}

acute poisoning were survived without disability and only $21(27.6 \%)$ were died. Above half $49(64.5 \%)$ of patents were take the poisoning deliberately (Table 2).

\section{Classification of substances taken by patients and type of treatment given}

From poisoning substances pesticides $20(26.3 \%)$ were highly identified followed by rat poisoning chemicals 15(19.8\%) and also only organophosphate materials were rarely identified $3(3.9 \%)$ followed by snake bite 4(5.3\%). From type of treatment given fluid resuscitation $21(27.6 \%)$ was the best way to manage the acute poisoning followed by gastric lavage $17(22.4 \%)$ and only few 4(5.3\%) of antidote management and emesis were used to manage the acute poisoning at emergency department (Table 3).

\section{Factors associated with acute poisoning outcome of socio- demographic characteristics of patients}

In present study socio demographic characteristics of patients assessed during intervention period were considered for binary logistic analysis as associated factor of acute poisoning occurrence. Of these, age, sex, residency, marital status, residency, and living condition were considered for multivariate logistic analysis. Patients whose age between $0-12$ years were 3 times more likely cause acute poisoning $(\mathrm{AOR}=3.10$, 95\%CI: $2.920-6.321, p=0.007)$ than others age category. Being male were 1.87 times more likely cause acute poisoning (AOR=1.87, 95\%CI: 1.941-2.216, $p=0.005)$ rather than male. Participants who were dwell in rural area 2 times more likely cause acute poisoning $(\mathrm{AOR}=2.31$, 95\%CI: $2.410-3.819, p=0.016)$ than those who dwell in urban area. Being divorced were 4.5 times more likely cause acute poisoning (AOR $=4.5,95 \% \mathrm{CI}: 4.673-9.312, p=0.001)$ than the left marital status. Living in house alone were 3 times more likely cause acute poisoning
(AOR=3.21, 95\%CI: 3.975-7.312, $p=0.049)$ than those who lived with family/friends or others (Table 4).

\section{Discussion}

As the majority of the Ethiopian population makes a living on agriculture, pesticides and insecticides are widely used in the population. Even though they are useful adjuncts to increase productivity, they are causing a significant collateral damage to the community. They cause serious harm to humans upon exposure. Accidental or intentional (suicidal/homicidal) exposure of humans leads to serious morbidity and mortality [16].

In this study the prevalence of acute poisoning was occurred $64.5 \%$ and $35.5 \%$ deliberately and accidentally respectively were in line with the study conducted in Selected Hospitals of Western Ethiopia [17] in which incidence of poisoning in nearly half $46.45 \%$ and $35.54 \%$ of the victims was, respectively, intentional and accidental. The similarity was due to the study subjects were dwell in the likewise region and majority of the participants are willing to suicide themselves deliberately during they feel angry due to they face bad challenges such as their loved people may died by others, more chronic disease, if they quarrel with others. This study was also inline to the survey conducted in India [18] which assessed the prevalence and mortality incidence rate due to various poisoning agents found that $68.40 \%$ of cases were due to intentional poisoning and $31.60 \%$ were due to accidental poisoning. Here in India somewhat high victims died by acute poisoning deliberately than this study and in this study accidental acute poisoning was slightly higher because the victims test the poison unknowingly in home or at work place.

The present study revealed that from poisoning substances herbicides $26.3 \%$ were highly identified followed by rat poisoning chemicals $19.8 \%$ were contrary to the study conducted in Hospitals of Kampala City [19] which showed dramatic increase in the number of pesticide poisoning from 2010 to 2011 compared with that happened from 2011 to 2014.This because majority of African population depends on agricultures so they bought pesticides to diminish weed from their crops and when feel bad they drunk it to kill themselves knowingly and only few of victims such as children drunk it unintentionally. This study showed the affected age of victims were between $0-12$ years $35.5 \%$ followed by $13-19$ years $27.6 \%$ contrary to the survey done in Hospitals of Kampala City the most affected age group was between 21 and 30 years. The differences were due to children take into mouth whatever they saw, they might not be able to read the instruction and no good care for the patients in rural area especially during farm.

The current survey revealed that $57.9 \%$ participants were males affected by acute poisoning were consistent with the survey in Tanzania [20] which showed majority of acute poisoning among patients presenting to ED of Tanzania are males, with a 3:1 female to female ratio. The similarity was due to males were more sensitive to decide the decision and they face quarrel more than females, so they were highly suicide themselves highly than females. In this study majority $44.7 \%$ of participants takes poisoning through oral ingestion followed by direct contact $23.7 \%$ were in line with the study employed in Ethiopia [21] which showed oral ingestion is identified as the primary route of poisoning. This likewise were due to majority the victims drunk pesticides or swallow rat poisoning chemicals to suicide themselves.

This study showed that $27.6 \%$ ( 21 cases) of victims died by acute poisoning were higher than the survey conducted in Debretabor General Hospital [22] that revealed the mortality rate from poisoning is around 
Bereda G (2021) Occurrence, overall rate and prognosticators of acute poisoning in emergency department of Mettu Karl Referral Hospital, Southwest Oromia, Ethiopia: A retrospective cross-sectional study

$18.6 \%$ (19 cases). This was the time elapsed since exposure to arrival at hospital of majority $41(53.9 \%)$ patients were $>4$ hours due to majority of victims home where far apart from the health centre/hospitals they didn't acquire management suddenly. In our study only $7.9 \%$ pharmaceuticals (drugs) were involved in acute poisoning occurrence were contrary to the survey conducted in University Medical Center at Stony Brook [23] in symptomatic patients exposed to potentially fatal medications (e.g., tricyclic antidepressants, monoamine oxidase inhibitors, calcium antagonists, cardiac glycosides, acetaminophen, theophylline, methanol, and ethylene glycol, admission to the hospital is usually clearly indicated. This was due to victims in this study were not got drugs which cause acute poisoning and also, they don't comprehend that the drug toxicities where kill him since majority of them were survived in the rural area without education.

In this study the occurrence of acute poisoning was high in in June-Aug (Summer) 46.1\% and low in Sept-Nov (Autumn) 11.8\% were consistent with the study conducted in Selected Hospitals in Western Ethiopia [17] which revealed the months from December to February were found to be a point in time when maximum poisoning cases were admitted. On the other hand, the incidence was observed to steadily decrease for other seasons up to its lowest record in the months from September to November. This likewise were because summer where the season the farmers farm the land seed the crops and the season the pesticides where highly avail at the markets so because of that most victims suffered by acute poisoning at June- Aug (Summer).

In this study from type of treatment given fluid resuscitation $27.6 \%$ was the best way to manage the acute poisoning followed by gastric lavage $22.4 \%$ were inconsistent with the study done in Hospitals of Kampala City [19] which showed the ABC protocol where they assess whether the airway is not blocked, breathing is normal, and circulation is good were the most undertaken measurements to manage acute poisoning. The differences were due to fluid resuscitation and gastric lavage perhaps common to manage the acute poisoning suddenly.

In present study socio demographic characteristics of patients assessed during intervention period were considered for binary logistic analysis as associated factor of acute poisoning occurrence. Of these age, sex, residency, marital status, residency, and living condition were considered for multivariate logistic analysis. Patients whose age between 0 - 12 years were 3 times more likely cause acute poisoning $(\mathrm{AOR}=3.10$, 95\%CI: 2.920-6.321, $p=0.007)$ than other age categories. Being male were 1.87 times more likely cause acute poisoning (AOR=1.87, 95\%CI: 1.941-2.216, $p=0.005)$ rather than male. Participants who were dwell in rural area 2 times more likely cause acute poisoning $(\mathrm{AOR}=2.31$, 95\%CI: 2.410-3.819, $p=0.016)$ than those who dwell in urban area. Being divorced were 4.5 times more likely cause acute poisoning ( $\mathrm{AOR}=4.5,95 \% \mathrm{CI}$ : 4.673-9.312, $p=0.001$ ) than the left marital status. Living in house alone were 3 times more likely cause acute poisoning $(\mathrm{AOR}=3.21,95 \% \mathrm{CI}: 3.975-7.312, p=0.049)$ than those who lived with family/friends or others.

\section{Conclusion and recommendations}

The prevalence of acute poisoning was high in the victims drunk the pesticides during the summer season. A majority of acute poisoning were survived without disability and only were died. Above half of patents were take the poisoning deliberately. Concerning marital status majority of patients were single and were divorced. Only few of antidote management and emesis were used to manage the acute poisoning at emergency department. Creating awareness about proper handling of chemicals and prescribed drugs in the society should be design and implemented by FMOH and also Mettu Karl Referral Hospital should have to advice the community, through different mechanisms especially for the youth. EFMHACA and Ministry of Agriculture must control agrochemical substances to minimize their open market sales and promote their rational use, which in turn might contribute to reducing the prevalence of acute poisoning.

\section{Acknowledgments}

The author extends his gratitude for data collectors for they bestow their thoroughgoing time to us.

\section{Conflict of interests}

Author declares that there is no conflict of interest to be disclosed.

\section{Funding}

None

\section{References}

1. Maheswari E, Abraham L, Chacko CS, Saraswathy GR, Ramesh AC (2016) Assessment of Pattern, Severity and Outcome of Poisoning in Emergency Care Unit. J App Pharm Sci 6: 178-183.

2. Jesslin J, Adepu R, Churi S (2010) Assessment of prevalence and mortality incidences due to poisoning in a South Indian tertiary care teaching hospital. Indian J Pharm Sci 72: 587-591. [Crossref]

3. Murray., L. 2004. General principles in the management of drug overdose. In: Cameron P, Jelinek G, Kelly AM, et al. Adult Emergency Medicine. 2nd Edn. Edinburgh: Churchill Livingston.

4. Malangu N, Ogunbanjo GA (2009) A profile of acute poisoning at selected hospitals in South Africa. South African J Epidemiol Infection 24: 14-16.

5. Waugh J, Najafi J, Hawkins L, Hill SL, Eddleston M, et al. (2016) Epidemiology and clinical features of toxicity following recreational use of synthetic cannabinoid receptor agonists: a report from the United Kingdom National Poisons Information Service. Clin Toxicol (Phila) 54: 512-518. [Crossref]

6. Singh O, Javeri Y, Juneja D, Gupta M, Singh G, et al. (2011) Profile and outcome of patients with acute toxicity admitted in intensive care unit: Experiences from a major corporate hospital in urban India. Indian J Anaesth 55: 370-374. [Crossref]

7. Islambulchilar M, Islambulchilar Z, Kargar-Maher MH (2009) Acute adult poisoning cases admitted to a university hospital in Tabriz, Iran. Hum Exp Toxicol 28: 185-190. [Crossref]

8. Bundotich JK, Gichuhi MM (2015) Acute poisoning in the Rift Valley Provincia General Hospital, Nakuru, Kenya: January to June 2015. S Afr Fam Pract 56: 1-5.

9. World Health Organization (2010) The international program on chemical safety (IPCS). Poisoning prevention and management, Geneva.

10. WHO Progress report (2013) Towards universal access:scaling up priority HIV/AIDS interventions in the health sector.

11. Committee on Poison Prevention and Control, Board on Health Promotion and Disease Prevention, Instit. Magnitude of the problem (2014) In: Forging a Poison Prevention and Control System, National Academies Press, Washington DC 43

12. World Health Organization (2014) Poisons information, prevention and management Geneva: WHO.

13. Abd-Elhaleem ZAE, Muqhem BAA (2014) Pattern of Acute Poisoning in Al Majmaah Region, Saudi Arabia. Am J Clin Exp Med 2: 79-85.

14. Mehrpour O, Jafarzadeh M, Abdollahi M (2012) A systematic review of aluminium phosphide poisoning. Arh Hig Rada Toksikol 63: 61-73. [Crossref]

15. Desalew M, Aklilu A, Amanuel A, Addisu M, Ethiopia T (2011) Pattern of acute adult poisoning at Tikur Anbessa specialized teaching hospital, a retrospective study, Ethiopia. Hum Exp Toxicol 30: 523-527. [Crossref]

16. Sawalha AF, Sweileh WM, Tufaha MT, Al-Jabi DY (2010) Analysis of the pattern of acute poisoning in patients admitted to a governmental hospital in Palestine. Basic Clin Pharmacol Toxicol 107: 914-918. [Crossref]

17. Woyessa AH, Palanichamy T (2020) Patterns, Associated Factors, and Clinical Outcomes of Poisoning among Poisoning Cases Presented to Selected Hospitals in Western Ethiopia: Hospital-Based Study. Emerg Med Int 2020: 5741692. [Crossref] 
Bereda G (2021) Occurrence, overall rate and prognosticators of acute poisoning in emergency department of Mettu Karl Referral Hospital, Southwest Oromia, Ethiopia: A retrospective cross-sectional study

18. Kumar MR, Kumar GP, Babu PR, Kumar SS, Subrahmanyam BV, et al. (2014) A retrospective analysis of acute organophosphorus poisoning cases admitted to the tertiary care teaching hospital in South India. Ann Afr Med 13: 71-75. [Crossref]

19. Ssemugabo C, Halage AA, Neebye RM, Nabankema V, Kasule MM, et al. (2017) Prevalence, Circumstances, and Management of Acute Pesticide Poisoning in Hospitals in Kampala City, Uganda. Environ Health Insights 11: 1178630217728924. [Crossref]

20. Mbarouk GS, Sawe HR, Mfinanga JA, Stein J, Levin S, et al. (2017) Patients with acute poisoning presenting to an urban emergency department of a tertiary hospital in Tanzania. BMC Res Notes 10: 482. [Crossref]
21. Chelkeba L, Mulatu A, Feyissa D, Bekele F, Tesfaye BT (2018) Patterns and epidemiology of acute poisoning in Ethiopia: systematic review of observational studies. Arch Public Health 76: 34. [Crossref]

22. Endayehu Y, Shenkutie E (2019) Magnitude of Acute Poisoning and Associated Factors in Debretabor General Hospital, Ethiopia. J Clin Toxicol 9: 5.

23. Hollander JE, McCracken G, Johnson S, Valentine SM, Shih RD (1999) Emergency department observation of poisoned patients: how long is necessary? Acad Emerg Med 6: 887-894. [Crossref]

Copyright: (C2021 Bereda G. This is an open-access article distributed under the terms of the Creative Commons Attribution License, which permits unrestricted use, distribution, and reproduction in any medium, provided the original author and source are credited. 